\title{
Comparison of cardioprotective effects using salvianolic acid $B$ and benazepril for the treatment of chronic myocardial infarction in rats
}

\author{
Haibo He • Mengqiong Shi • Xianzhe Yang • \\ Xiaowei Zeng $\cdot$ Limao Wu $\cdot$ Lianda Li
}

Published online: 24 April 2009

(C) Springer-Verlag 2009

\section{Erratum to: Naunyn-Schmiedeberg's Arch Pharmacol (2008) 378:311-322 \\ DOI 10.1007/s00210-008-0287-6}

It has come to the attention of the journal, that an article published last year (He et al. 2008a) contains largely the same or largely overlapping data as two other articles published by the same authors concomitantly elsewhere (He et al. 2008b, 2008c) without cross-referencing of these manuscripts. The journal has come to the conclusion that this constitutes selfplagiarism and hence has decided to retract the paper.

\section{References}

He H, Shi M, Yang X, Zeng Z, Wu L, Li L (2008a) Comparison of cardioprotective effects using salvianolic acid $\mathrm{B}$ and benazepril for the treatment of chronic myocardial infarction in rats. Naunyn-Schmiedeberg's Arch Pharmacol 378:311-322

He H-B, Yang X-Z, Shi M-Q, Zeng Z-W, Wu L-M, Li L-D (2008b) Comparison of cardioprotective effects of salvianolic acid B and benazepril on large myocardial infarction in rats. Pharmacol Rep 60:369-381

He H, Shi M, Zeng X, Yang J, Li Y, Wu L, Li L (2008c) Cardioprotective effect of salvianolic acid B on large myocardial infarction mediated by reversing upregulation of leptin, endothelin pathways, and abrnomal expression of SERCA2a, phospholamban in rats. J Ethnopharmacol 118:34-35

The online version of the original article can be found at http://dx.doi.org/ 10.1007/s00210-008-0287-6. 